\title{
A concurrent pilot project approach to approval plans
}

\author{
Tony Horava \\ Collection and Information Resources Coordinator, University of Ottawa, Canada
}

Available online 7 September 2006

\begin{abstract}
The University of Ottawa, Canada, adopted a concurrent pilot project strategy for implementing a US and UK book approval plan. This meant that two vendors were simultaneously piloted for the services they could provide, and this allowed for a direct comparison between vendors. Timelines and objectives were determined. At the end of the process, a single vendor was selected as the provider for approval books in the humanities, social sciences, and health sciences. The process was timeconsuming but proved an excellent learning experience in understanding vendor systems and capabilities. It allowed library staff to compare vendors in a tangible manner, and to make wellinformed decisions on vendor approval plans.
\end{abstract}

(C) 2006 Elsevier Inc. All rights reserved.

Keywords: Acquisitions; Approval plans; Collection development

\section{Introduction}

Approval plans are an integral component in the collection development strategy of most academic libraries today (and many non-academic libraries as well). Collection development and the acquisitions process face a greater complexity of issues and range of expectations needs than ever before. New research areas, new programs, expectations of transparency in budget allocation, an explosion of new resources in digital formats, and enhanced vendor systems are a few of the major factors in our information landscape. Vendors offer more and

E-mail address: thorava@uottawa.ca. 
more options and services, such as electronic ordering, retrospective subject coverage, greatly enhanced user interfaces, and enriched content such as tables of contents and summaries. It is a time of dynamic change. Approval plans play a vital role in this landscape, and represent a significant investment of time and energy on the part of many library staff. This paper will provide an overview of the University of Ottawa's approach to approval plan implementation, which involved a concurrent pilot project with multiple vendors. The background, issues, challenges, and outcomes will be presented.

The University of Ottawa is a comprehensive doctoral university in Canada's capital, Ottawa, located in Ontario. It offers 230 programs in ten faculties (Arts, Social Sciences, Education, Management, Engineering, Science, Law, Medicine, Health Sciences, and Graduate Studies). In 2004-2005, there were 31,439 students including 27,603 undergraduates and 3838 at the Masters and $\mathrm{PhD}$ level. The libraries are comprised of: the Morisset Arts and Sciences Library, the Brian Dickson Law Library, the Health Sciences Library, and the Music library. The acquisitions budget in 2005-2006 was approximately nine million dollars. Building a bilingual collection at a research level is a key element in our collection development strategy, since instruction is offered in both French and English in all programs.

One of our key aims for approval plans was to help develop a core English-language collection in various subject areas, thus freeing the librarian to focus on material from nontraditional and smaller publishers, non-English titles, and newer, more specialized areas of interest. As Eldridge has said, "Approval Plans should be relied upon to deliver the easily accessible, obvious material the library is expected to have available for use. This includes material produced by the major publishers in each subject area needed and material reviewed by the major reviewing sources" [1]. The 80/20 rule can be generally applied: we wanted our librarians to focus most of their time on identifying and selecting the small number of titles and sources that require their expertise and knowledge, while allowing the vendor to supply a large quantity of titles from major publishers according to the established profiles. Multidisciplinary coverage was important.

Various academic libraries have chosen to issue a formal RFP to select an approval plan vendor. This invites vendors to put on their best face, so to speak, and make various promises about their performance and service. Pricing often drives the process and decision-making. However, there are hidden costs of dealing with unexpected problems that can be like the iceberg that is mostly hidden under the surface of the water. A vendor's implementation of a new software release or major internal procedural change can have a significant impact on performance. Customer service may not be up to scratch. The profile creation and management process may be different from what was expected. The realities of daily work can intrude into the vendor's RFP promises in a hundred ways. Upgrades or new releases of a vendor's platform can have major impacts - good or bad - on the staff that depends on the system to achieve their objectives. Matthews notes that an RFP "...does not focus on the vendor's track record for delivering new releases of software in a planned and orderly manner" [2]. Our experience confirmed that vendors differ widely in this respect, and the implications cannot be underestimated. Corporate cultures differ from one vendor to another, and this will have consequences on how well the vendor-library relationship is developed. Schachter points out that "Culture fit is non-quantifiable, yet you must estimate how the vendor's culture will mesh 
with your organization, otherwise you will find a crisis in communication and resistance on both sides" [3]. This is an intangible of large proportions that cannot be assessed by the quantifications in an RFP, or even an RFI.

\section{New directions}

Prior to 2002, we managed an English-Canadian book approval plan with Coutts and a French-Canadian book approval plan with Renaud Bray. These expenditures represented a small percentage of the total monograph budget, as the Canadian academic publishing output is very small compared internationally. In 2002, the University of Ottawa libraries decided that expanded approval plans should be an important component of its strategic direction. There were several factors that contributed to this decision: (1) the need for subject librarians to focus on information literacy activities with their faculty and students; (2) the growth in the acquisitions budget, which had been very poor in the 1990s but was now increasing as the university administration understood the critical need to bolster the library collection in relation to the university's mission; (3) the burgeoning growth in the number of students; (4) the creation of new programs that were highly interdisciplinary; (5) the ubiquitous rise in interdisciplinarity across all areas of research, scholarship, and teaching; and (6) limited staff resources, both professional and non-professional, which meant that refocusing librarians activities and creating efficiencies in processing operations was critical.

The pilot project approach was also informed by sensitivity to the concerns of librarians who had been working their entire careers without approval plans (with the exception of Canadian plan mentioned above). One could not expect all librarians to warm up to the idea of entrusting a vendor with helping to develop the collection using approval plans. Enrollment projections revealed a marked upward trend in the coming decade, driven by such factors as the phasing out of Grade 13 at the secondary level in Ontario, the new emphasis on lifelong learning, and the need for many individuals to return to university to upgrade their knowledge and skills. The mushrooming of new programs, institutes, and research centers at the confluence of existing disciplines meant a reexamination of the ways in which subjects were defined and collected. Last but certainly not least was the central administration's growing awareness of the need to invest monies in our collection that were comparable with peer institutions. Our collections budget had been chronically under funded in the 1990s, and now a catch-up process was being developed.

\section{First phase}

It was judged appropriate to establish pilot projects with two of our major vendors who offer approval plan services, namely Coutts and Blackwells. We had business relationships with these vendors dating back many years (firm orders, standing orders, and in the case of Coutts, a pre-existing approval plan for English-Canadian monographs including shelf-ready treatment); therefore, it was not a case of starting cold. We informed both vendors of our 
intention to conduct a sixteen-month pilot project for a book approval plan in a number of selected disciplines, from September 2002 to December 2003. By setting up parallel pilot projects with both vendors, we served notice that we were interested in what they could offer but we were actively comparing their performance. This ensured that we were not locked in to a long-term agreement with any vendor, while allowing the collections librarians and acquisitions staff to gain hands-on experience with these vendors' systems, practices, and procedures. We selected a variety of disciplines in the social sciences and humanities where approval plans were deemed to be feasible, and created a cluster for each vendor. The Blackwells' grouping included English Literature, Psychology, Economics, Management, Human Kinetics, and Education. The Coutts' grouping included Sociology, Political Science, Criminology, and Women's Studies. Staff briefings were held, and the collections librarians were interviewed by the vendor representatives in order to create subject profiles. We decide to set up separate profiles for each discipline, as this was a pilot phase. Cost estimates were obtained from the vendors.

Technical services staff were involved in setting up the acquisitions and cataloguing functionality of the project (e.g. the use of the acquisitions interface for daily activities such as reception and payment issues, claiming, book returns, and the setting up of a MARC record service via ftp). Procedures for viewing and assessing the books, returning books, adjusting the profiles, and fund payment were put into place. Librarians could view the books in a designated room and determine whether the books should be kept or not. The Collections Coordinator reviewed the 'problem books' and consulted with the librarians and the vendor to make changes to the profile as needed. As librarians already had familiarity with the databases of these two vendors, this was an advantage. Further training was provided to librarians by the vendors. Implementing these approval plans meant that the librarians would be using the vendor databases in a more intensive and regular manner than before. I should also add that we decided to send firm orders for the disciplines in question to the approval plan vendor, in order to control duplicates, invoicing, and achieve efficiencies in ordering.

By implementing two simultaneous pilot projects with major vendors, we were able to assess the strengths and weaknesses of each vendor. There is certainly no vendor out which will perfectly meet the needs of every library. Moreover, approval plans now encompass a wide area of potential activities - selection work and collection development; acquisitions and payment; continuations and serials; cataloguing and shelf-ready treatment. Various new services such as ebook notification and ordering, selection lists (such as award winners), sophisticated analytical reports, and faculty alerts for new titles are being developed by vendors. These value-added capabilities are changing the library's expectations of a book vendor's performance. These issues cannot be assessed individually but must be seen as part of an integrated whole that profoundly affects the library's activities at both the strategic and operational levels. While comparing costs and performance is always important, the vendorlibrary relationship is the intangible element that determines the success of the outcome. An approval plan is a commitment that requires much time and energy on both sides. As Bostic aptly points out, "The evidence seems to support the general statement that an approval plan has the best chance of success when there exists an understanding of the dynamics of approval buying on the part of both librarians and faculty, where there is sufficient pre- and post- 
implementation planning and coordination, and when there exists a positive and mutually supportive relationship between the approval plan representative and the library. Perhaps the key is the human factor" [4]. The need for ongoing planning and coordination was certainly borne out in our experience. An approval plan is a complex instrument that involves many players and various expectations on both sides of the relationship.

After the pilot period was over, we assessed the vendors' performance from a number of perspectives - profile performance in terms of relevance and quantity of books received; returns; costs and business terms; profile creation and adjustment; user interface for functionality, content, and ease of use; acquisitions issues such as invoicing, claiming, and payment, control of doubles, actual costs versus vendor estimates, and control of paper versus cloth editions. The relationship factor was highly important, as this impacted day-to-day customer service and resolution of specific problems. Qualitative and quantitative issues were examined.

Based on our analysis of the pilot, we decided to retain our Blackwells plan and discontinue the Coutts' plan since the plan offered by Blackwells best suited our needs. We met with the Coutts' representatives and explained the reasons for our decision. As we kept our English Canadian plan with Coutts, this was a realignment rather than a complete break with this vendor.

\section{Second phase}

At this time we also became aware of another major vendor for US and UK books, namely Yankee Book Peddler (YBP). We investigated their services, obtained testimonials from various Canadian libraries, and decided to embark on a pilot project with YBP for US books. This commenced in October 2004, following discussions with YBP about our objectives and our interests. YBP was a new vendor for us, and therefore we had to start from scratch in developing practices and policies regarding approval plans, and negotiating the terms and procedures. Profiling sessions were held with the librarians in August, and the implementation began in October.

This became the second phase of our approval plan pilot strategy. The disciplines formerly assigned to Coutts were now transferred to YBP. Human Kinetics was also transferred to YBP from Blackwells, based on input from the subject specialist. As the Blackwells pilot was still in place, we now had the opportunity to compare YBP with Blackwells. It was understood that the pilot would last one year, and that an evaluation would then take place. This ensured that neither vendor felt complacent nor believed that they could count on future business. We negotiated a memorandum of agreement with YBP, and the vendor representative came to Ottawa and interviewed the relevant librarians to create profiles in the selected disciplines. A MARC record service was set up with our cataloguing department. Training was provided to the librarians on the vendor database, and acquisitions procedures were put into place. As the year progressed, we made profile changes, returned books as appropriate, and monitored the performance of the plan and the reactions of staff.

The assessment focused on the same areas as mentioned above. There was no perfect vendor, and both were seen to have strengths and weaknesses. We needed to evaluate our 
experience with these two vendors with thoroughness, impartiality, and a cost/benefit approach. Librarians and support staff had their own likes and dislikes in relation to these vendors, and we needed to focus on the empirical evidence. Vendor evaluation is a complex and multi-layered affair. It came down to an analysis of which vendor was a better fit for our library, all things considered. We assessed YBP and Blackwells according to the criteria used in the earlier phase. This was a challenging exercise since it required a comprehensive overview of the key performance indicators, and we needed to compare 'apples with apples'. Majors had recently been acquired by Baker and Taylor (YBP's parent company) and this also had a bearing on our decision, since we had a Health Sciences approval plan with Majors and needed to find an alternative.

The analysis led us to conclude that YBP was the better vendor to meet our strategic requirements and position us for responding to the changing dynamics in collection development. We informed both vendors about our decision. During 2006, we will be implementing a wider approval plan with YBP, including the disciplines formerly assigned to Blackwells, as well as others. As firm orders are placed with the same vendor as approval orders, YBP will become our principal US and UK vendor for humanities, social sciences, and health sciences in 2006. We are retaining our relationship with the other major vendors, in order to use them as appropriate, and to not close any doors. Assessment is an ongoing process, and we will be actively assessing YBP's performance during the coming year. Twiest makes an important point when he states that "Even without funding pressure good management dictates that knowledge about vendor performance become a part of the decision-making process in selecting or remaining with a particular vendor. Too many managers evaluate vendors at the "gut feeling" level apart from hard cold fact" [5]. Evaluation is a time-consuming business, for sure, but it focuses the library on prioritizing what is important and on judging the relative merits of different vendors, apart from timeworn assumptions. The result is an objective, cleareyed decision based on selecting a vendor can best meet the library's requirements. This was our experience.

\section{Conclusions}

The process that I have described has taken three years, which is longer than we had expected at the outset. For many schools, this may seem like an eternity, considering the pressures to reform practices and procedures in collection development, and achieve greater efficiencies. There has been a major investment of time and energy on the part of many librarians and support staff in this process. However, we felt that since this was a major change in collection development and acquisitions activities, we needed to invest the time needed for this process. There have been a number of advantages, some planned and some unplanned. We have acquired experience with three of the most important approval book vendors in North America. This has revealed to us the strengths and weaknesses of their service and performance as it relates to our requirements and our culture. This would not have been possible with an RFP or RFI process, or with a vendor demonstration approach. There are too many unknowns and too many points of interaction where the vendor-library relationship. We 
also discovered the value of experience accumulated over time. Flowers says that "An approval plan requires ongoing not just one-time negotiations. There are many possible areas of change. They range from money available, new curricula at the institution, expanded coverage from the vendor, etc." [6]. During the preceding three years, we saw all of this and more - increases to the acquisitions budget; new academic programs; a new strategic plan for the university; new features and functionality offered by the vendors' platforms (both for selection and acquisitions); changing staff and new corporate directions for the vendors involved. All of this had an impact on our assessment.

The three years also allowed for our librarians and support staff to become more familiar and comfortable with approval plans as an integral aspect of collection development. There have also been many changes in librarian staffing, and the new librarians are generally in agreement with the philosophy of approval plans. The librarians have heavy workloads and are recognizing that approval plans are a means to enable them to meet their collection development goals while ensuring that they retain ownership and involvement in the process. This accords with Nardini's view of the profiling process: "The representative should attempt to help define library needs, weigh them realistically against vendor capabilities, and make sure all the while that end specifications intersect with book publishing actualities. The process can be an exercise in communication and self-definition for library and vendor alike" [7]. While it is quite true that this is an exercise in self-definition, it is by nature an evolutionary process, for a library's directions and goals are not static but continually evolving as the institution evolves in a rapidly changing socioeconomic environment.

We gained much knowledge about the vendors and their staff, and how they deal with communication, customer relations, and problem solving. We were able to compare types of treatment (book in hand versus automatic matching), book costs and publisher coverage, profile creation and management, platform functionality, rates of returns, control of doubles, fill rates, invoicing, the MARC record service, and contractual issues. Most of all, we were able to see at first hand how critical is the human element in determining the degree of success in the library-vendor relationship. Our iterative approach has required substantial time and effort, and may not suit the circumstances of many other libraries, but it has suited our organizational culture and environment. As we move forward to a wider implementation of approval plans, our experience has sharpened our understanding of the many issues involved, and greatly lessened the surprise element.

\section{References}

[1] Eldredge, M. (1996). Major issues in approval plans: The case for active management. Acquisitions Librarian, (16), 51-59.

[2] Matthews, J. R. (1994). Do you need an RFP? College and Undergraduate Libraries, 1(2), 55-64.

[3] Schachter, D. (2004). How to manage the RFP process. Information Outlook, 8(11), 10-12.

[4] Bostic, M. J. (1991). Approval acquisitions and vendor relations: An overview. Acquisitions Librarian, (5), 129-144.

[5] Twiest, D. A. (1988). Vendor evaluation for the small academic library. Christian Librarian, 31(2), 33-35.

[6] Flowers, J. L. (2004). Specific tips for negotiations with library materials vendors depending upon acquisitions method. Library Collections, Acquisitions, and Technical Services, 28, 433-438. 
[7] Nardini, R. F. (1994). The approval plan profiling session. Library Acquisitions: Practice and Theory, 18(3), 289-295.

\section{Additional resources}

Barker, J. W. (1989). Vendor studies redux: Evaluating the approval plan option from within. Acquisitions: Practice and Theory, 13(2), 133-141.

Chalaron, P., \& Perrault, A. (1991). Approval plans: The multi-vendor approach. Acquisitions Librarian, (5), $145-159$.

Gelbwasser, S. E. (1996). Vendor library relationships in ARL libraries. Acquisitions Librarian, (16), 109-117. 